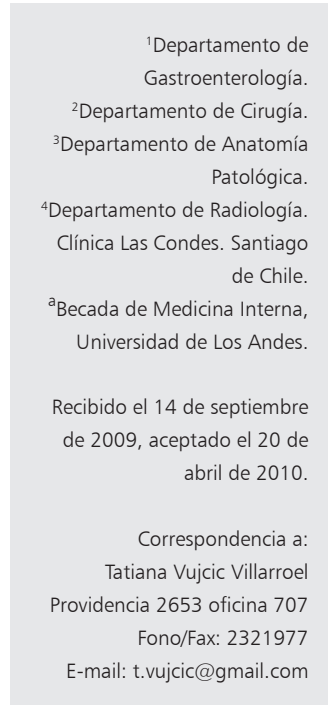

\section{Metástasis pancreáticas tardías
undarias a cáncer de células renales: \\ Metástasis pancreáticas tardías
secundarias a cáncer de células renales: Caso clínico}

\author{
TATIANA VUJCIC ${ }^{\text {a }}$, JAVIER BRAHM ${ }^{1}$, ERWIN BUCKEL ${ }^{2}$, \\ ÁLVARO IBARRA ${ }^{3}$, MARÍA TERESA VIAL $^{3}$, MANUEL FERNÁNDEZ $^{4}$
}

\section{Pancreatic metastasis from renal cell carcinoma: A case report}

\begin{abstract}
We report the case of a 60 year old woman with multiple pancreatic nodules found on abdominal computed tomography. Thirteen years earlier she had undergone a left nephrectomy for renal cell carcinoma. The patient underwent surgery with a preoperative diagnosis of multifocal metastatic or neuroendocrine tumor. At surgery, two metastatic nodules of renal cell carcinoma were found and excised. After four years of follow up there is no evidence of recurrence.
\end{abstract}

(Rev Med Chile 2010; 138: 738-741).

Key words: Carcinoma, renal cells; Neoplasm metastasis; Pancreatic neoplasms.
$\mathrm{L}$ as metástasis pancreáticas (MP) son poco comunes y difíciles de diferenciar de un tumor primario. Estas representan menos de $5 \%$ de las neoplasias pancreáticas ${ }^{1,2}$ y menos de $2 \%$ corresponden a metástasis solitarias ${ }^{3,4}$. Los tumores de pulmón, riñón, tracto gastrointestinal, mama y piel (melanoma) son los que más producen $\mathrm{MP}^{3,6,9}$. El carcinoma de células renales (CCR) representa $0,25 \%$ a $4 \%$ de éstos ${ }^{1-3,5}$.

La mayor parte de las MP son asintomáticas al momento del diagnóstico, y la lesión pancreática constituye en éstos casos un hallazgo incidental durante las autopsias o en la cirugía ${ }^{8,10,12}$.

Por otra parte, la experiencia que existe en resección de MP única es muy limitada9 ${ }^{9}$. La mayor parte de las publicaciones al respecto corresponden a comunicación de series de $\operatorname{casos}^{1,2,4,5,7,9,11,12}$. Hay también falta de información con respecto a la sobrevida luego de la resección y sus efectos en la calidad de vida ${ }^{1,2,5,7,9,12}$.

Presentamos un caso de MP tardía de un CCR y una revisión de la literatura relacionada.

\section{Caso clínico}

Mujer de 60 años, con antecedentes de hipernefroma izquierdo (sometida a una nefrectomía total el año 1991), hipotiroidea, dislipidémica, colecistectomizada, histerectomizada y con prótesis de cadera izquierda, en control habitual en Urología.

Fue derivada a gastroenterología en el año 2004, por hallazgo de varias imágenes nodulares pancreáticas en tomografía computada (TC). Dentro de los exámenes destacaban un perfil bioquímico, amilasa, lipasa y hemograma dentro de rangos normales y VHS de 42. Marcadores tumorales: antígeno carbohidrato (Ca 19-9) y antígeno carcinoembrionario (CEA) negativos.

Se continuó el estudio complementario con una colonoscopía, que mostró diverticulosis de colon descendente y pólipos en colon derecho (adenoma tubular con displasia moderada). Posteriormente se realizó una endosonografía que demostró duodeno y papila normales. Se observaron lesiones focales de páncreas con aspecto 


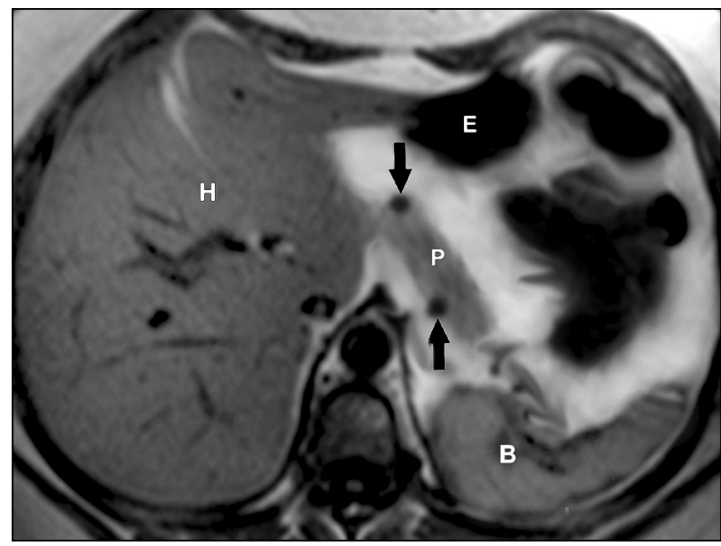

Figura 1. Resonancia magnética secuencia T1 FF. RM, T1-FF: En el páncreas (P) se observan dos imágenes bien delimitadas e hipointensas en relación al parénquima pancreático (flechas)، que se ubican en el cuerpo y cola del páncreas respectivamente. $(\mathrm{H})$ hígado, (B) bazo, (E) estómago.

sugerente de tumor neuroendocrino, sin poder descartar una lesión secundaria a CCR. Se tomaron biopsias de la lesión, siendo el estudio histológico no concluyente. La resonancia magnética (RM) mostró en la secuencia T1-FF un área hipointensa a nivel del cuerpo pancreático, borde anterior, y otra similar ubicada hacia la cola, borde posterior (Figura 1). En la secuencia T1 con gadolinio, estas imágenes eran muy hiperintensas, lo que reflejaba su naturaleza hipervascular (Figura 2). Estos hallazgos permitieron plantear los diagnósticos de neoplasia neuroendocrina o metástasis hipervasculares, sin que existieran elementos imagenológicos para diferenciarlas. Se discute el caso clínico, y dada la sospecha de metástasis de CCR o tumor neuroendocrino, se realizó en marzo de 2005 una pancreatoduodenectomía subtotal más esplenectomía.

El estudio anatomo-patológico confirmó los dos nódulos pancreáticos sólidos de 0,6 y de $0,7 \mathrm{~cm}$ (Figura 3). La inmunohistoquímica mostró positividad intensa en células tumorales para el antígeno epitelial de membrana (EMA), PAN citoqueratina (Pan-CK) (Figura 4), CD-10 (Figura5) $y$ vimentina en aproximadamente en $70 \%, 90 \%$, $60 \%$ y $100 \%$.

Evoluciona favorablemente en el post operatorio, con controles periódicos. TAC de abdomen en 2009 muestra la pancreatectomía distal, sin evidencias de recurrencia, y lo mismo se verificó

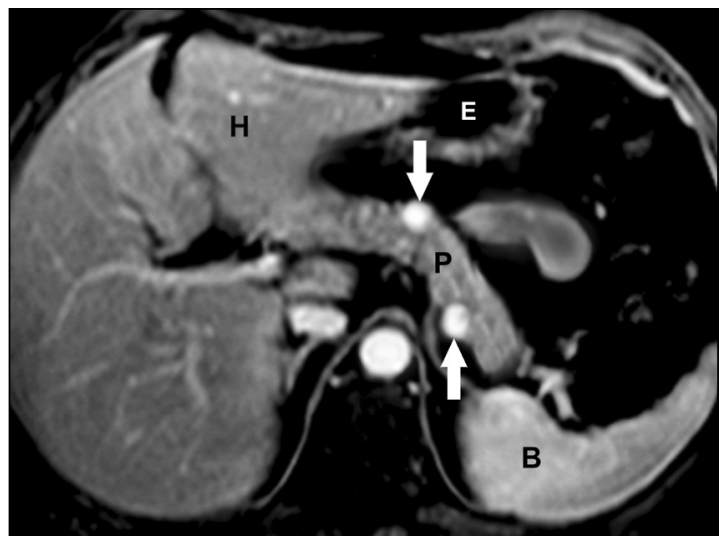

Figura 2. Resonancia magnética secuencia T1. Gadolinio. Fase arterial. RM, T1. Gadolinio, fase arterial: Las dos imágenes (flechas) del páncreas (P) se hacen marcadamente hiperintensas con el contraste, demostrando el carácter hipervascular de las lesiones. (H) hígado, (B) bazo, (E) estómago.

en TAC de abdomen en enero de 2010 y ecografía abdominal en abril de 2010 .

\section{Discusión}

El CCR afecta a pacientes en la sexta década de la vida, siendo el páncreas un sitio poco común para las metástasis ${ }^{1,4,5,9}$. Una de las particularidades del CCR es lo tardío (metacrónico) que puede ser el intervalo entre la nefrectomía y las MP, en especial aquellos CCR bien diferenciados. Se describe en algunos reportes hasta 32 años de diferencia ${ }^{1,5,7,8,9,11,13}$. Nuestra paciente tuvo 13 años entre la nefrectomía y las MP. Por otra parte, existe evidencia que $25 \%$ de los pacientes con CCR puede tener un foco metastático al momento del diagnóstico (sincrónico) $)^{1,7}$.

Dentro de las otras neoplasias que producen metástasis en páncreas están pulmón, mama, colon, melanoma y tiroides. Datos publicados con respecto a la distribución de éstos se basan en los hallazgos incidentales durante autopsias o la cirugía ${ }^{1-5,8,10}$.

En una serie de autopsias, Adsay et al documentaron que los tumores que mas producirán MP eran los de pulmón (42\%), seguido por los del tracto gastrointestinal $(24,7 \%)$ y CCR $(4 \%)^{10}$. Sin embargo, en reportes más recientes, se describe que los tumores encontrados durante la cirugía eran principalmente secundarios a $\mathrm{CCR}^{4}$. La vía 


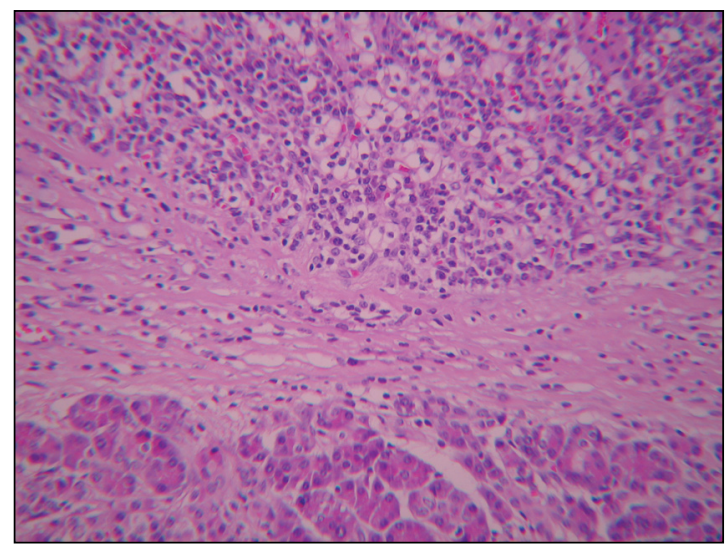

Figura 3. Anatomía patológica, tinción hematoxilina-eosina. Páncreas con metástasis de CCR, mitad superior (HE 100X).

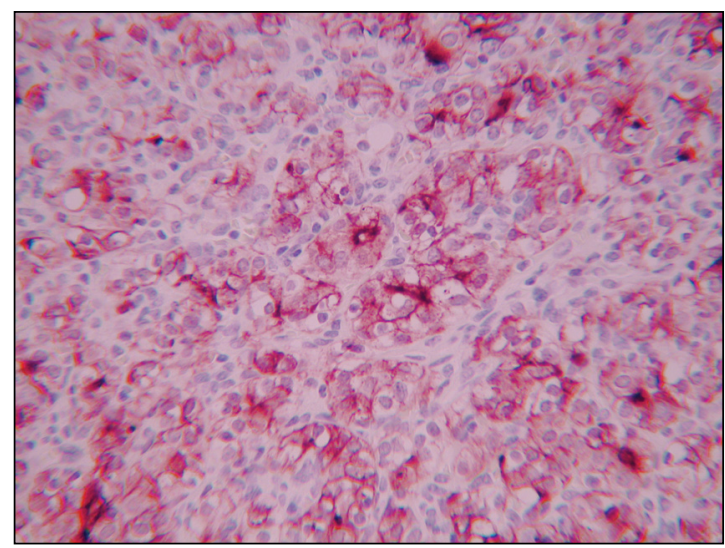

Figura 5. Inmunohistoquímica II. Inmunohistoquímica para CD-10, (400X)

de diseminación del CCR hacia el páncreas estaría dada tanto por ruta linfática, como por ruta venosa mediante shunts portorenales 9,11 .

Tiene gran importancia diferenciar entre metástasis y lesión primaria de páncreas, dadas las implicancias tanto en el manejo como en el pronóstico. La distinción entre ambas puede generar dificultad en el proceso diagnóstico, tal como se produjo en nuestra paciente, para lo cual existen elementos clínicos, imagenológicos, histológicos e inmunohistoquimícos, que ayudan al proceso diagnóstico ${ }^{8}$.

El diagnóstico de las MP constituye generalmente un hallazgo incidental durante el seguimiento del CCR ya que hasta $50 \%$ de los casos

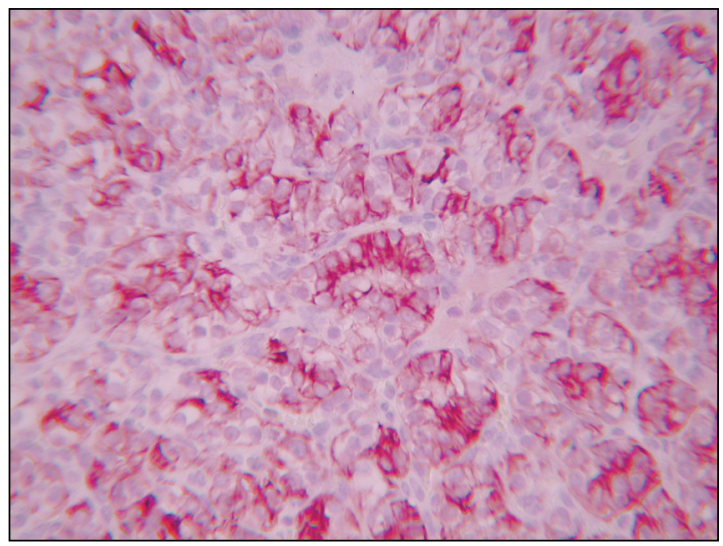

Figura 4. Inmunohistoquímica I. Inmunohistoquímica para PAN citoqueratina (400X)

pueden ser asintomáticos. El resto se pueden presentar como baja de peso, ictericia obstructiva, dolor abdominal o sangrado gastrointestinal ${ }^{1-4,7-9,11}$.

Dentro del estudio imagenológico, existen elementos que también nos van a orientar al diagnóstico. La TC y la RM son las técnicas de elección para el estudio ${ }^{1,7-9,13}$. Lesiones multifocales son altamente sugerentes de enfermedad diseminada. Tumores altamente vascularizados son más representativos de tumores neuroendocrinos o metástasis, no existiendo elementos que permitan diferenciarlos desde el punto de vista imagenológico. En cambio el cáncer de páncreas característicamente es hipovascular ${ }^{9,13}$.

Para lograr hacer la distinción, se deben buscar síntomas endocrinos en el interrogatorio dirigido. En nuestro caso, el principal diagnóstico diferencial dentro del estudio de imágenes fue un tumor de origen neuroendocrino, a pesar de que no existían elementos en la anamnesis que lo hicieran sospechar.

Cuando el diagnóstico permanece incierto, la biopsia (percutánea o endoscópica) mediante aspirado con aguja fina, sigue siendo el método de mayor rendimiento ${ }^{1,9,13}$. Sin embargo, existe un alto riesgo de sangrado durante el procedimiento dado su gran vasculatura, por lo cual en general no se indica y estos pacientes deben ir a cirugía $a^{8,9}$. La biopsia con aguja fina mediante endosonografía puede tener un menor riesgo y mayor rendimiento que la biopsia percutánea, dependiendo de la ubicación de la lesión ${ }^{1,8}$.

Con respecto a la inmunohistoquímica los 
Metástasis pancreáticas tardías secundarias a cáncer de células renales - T. Vujcic et al

marcadores EMA, PCK, CD-10 y vimentina característicos de CCR los que en nuestro caso fueron positivos $^{8}$. Este estudio histológico fue consistente con metástasis de CCR.

La sobrevida de los pacientes con un CCR con metástasis es pobre sin resección, siendo alrededor de $10 \%$ a los 5 años. Por lo tanto, el tratamiento de elección en la MP por CCR es la resección radical, ya que ésta logra aumentar significativamente la sobrevida del paciente, describiéndose en algunos reportes, hasta de $70 \%$ en 5 años ${ }^{1,2,5,7-12}$.

Existen factores de buen pronóstico, previo a la resección: 1) diferencia de más de 10 años entre el CCR y la MP; 2) evidencia de lesión solitaria en estudio radiológico; 3 ) regresión espontánea de la MP; 4) evidencia de necrosis extensa del tejido; 5) tumor de crecimiento lento y asintomático ${ }^{8}$.

Nuestra paciente lleva hasta la fecha más de 4 años desde la pancreatectomía, sin evidencias de recidiva en último control de TC.

Otros tratamientos como la quimioterapia, radioterapia y la hormonoterapia, no son efectivos para el CCR ni para sus metástasis ${ }^{8}$. Nuevas técnicas han sido propuestas y aplicadas recientemente, como la ablación con radiofrecuencia percutánea guiada con TC. Sin embargo, hay pocos reportes para esta técnica ${ }^{6}$.

En conclusión, las MP son poco frecuentes, debiendo ser diferenciadas del tumor pancreático primario (especialmente de tipo neuroendocrino), ya que tiene implicancias en el manejo y pronóstico. Deben ser tratados en forma agresiva, ya que la resección quirúrgica con pancreatectomía, aumentaría significativamente la sobrevida de éstos pacientes.

\section{Referencias}

1. Shola N, Prashant KJ, Alan P, Krishna VM. Synchronus Pancreatic Metastasis from asyntomatic Renal Cell Carcinoma. J Pancreas 2005; 6: 26-8.

2. Takayuki A, Eiji U, Kazuya Y, Hiroshi Y, Makoto H,
Takashi T. Surgical treatment for isolated multiple pancreatic metastases from renal cell carcinoma: report of a case. J Nippon Med Sch 2008; 75: 221-4.

3. Maeda A, Uesaka K, Matsunaga K, Kanemoto H, Bando E, Furukawa H. Metastatic tumors of the pancreas. Pancreas 2008; 37: 234-6.

4. Koide N, Yokoyama Y, Oda K, Nishio H, Ebata T, Abe T, et al. Pancreatic metastasis from renal cell carcinoma: results of the surgical management and pathologic findings. Pancreas 2008; 37: 104-7.

5. Stankard CHE MD, Karl RC MD. The treatment of isolate pancreatic metastases from renal carcinoma: a surgical review. A J Gastroenterology 1992; 87: 1658-60.

6. Carrafiello G, Laganà D, Recaldini C, Dionigi G, Boni L, Bacuzzi A, et al. Radiofrequency ablation of a pancreatic metastasis from renal cell carcinoma: case report. Surg Laparosc Endosc Percutan Tech 2008; 18: 64-6.

7. Bassi C, Butturini G, Falconi M, Sargenti M, Mantovani W, Pederzoli P. High recurrence rate after atypical resection for pancreatic metastases from renal cell carcinoma British Journal of Surgery 2003; 90: 555-9.

8. Thompson L, Heffess C. Renal cell carcinoma to the pancreas in surgical pathology material. Cancer 2000; 89: 1076-88.

9. Faure JP, Tuech JJ, Richer JJ, Pessaux P, Arnaud JP, Carretier M. Pancreatic metastasis of renal cell carcinoma: presentation, treatment and survival. J Urology 2001; 165: 20-2.

10. Adsay NV, Andea A, Basturk O, Kilinc N, Nassar H, Cheng JD. Secondary tumors of the pancreas: an analysis of a surgical and autopsy database and review of the literature. Virchows Arch 2004; 444: 527-5.

11. Kassabian A, Stein J, Jabbour N, Parsa K, Skinner D, Parekh D, et al. Renal cell carcinoma metastatic to the pancreas: a single-institution series and review of the literature. Urology 2000; 56: 211-5.

12. Alessandro Z, Enrico O, Gianpaolo B, Anna B, Aldo AB, Valerio DC. Pancreatic Metastasis from renal cell carcinoma: Which patients Benedit from surgical resection? Annals of Surgical Oncology 15: 1161-8.

13. Klein K, Stephens D, Welch T, CT Characteristics of Metastatic Disease of the Pancreas. Radiographics 1998; 18: 369-18. 